Subjects were classified as focal (fIS)(n=23) and diffuse (dIS)(n=46). ES responded to the initial ACTH trial in $100 \%$ fIS vs $80 \%$ of dIS $(\mathrm{p}=0.02)$. Subsequent seizure relapse occurred in $74 \%$ fIS cf $38 \%$ of the dIS group ( $p=0.0006)$. A second ACTH course of therapy in fIS group resulted in a short- or long-term remission. Approximately one-third of fIS patients maintained remission despite focal epileptic EEG abnormalities. Focal resection and corpus callostomy achieved only a short-term remission. Grouping patients as fIS and dIS provides practical information regarding long-term outcome and treatment strategies. (Fujii A, Oguni H, Hirano Y, Shioda M, Osawa M. A long-term, clinical study on symptomatic infantile spasms with focal features. Brain Dev 2013 May;35(5):37985). (Response: Dr Hirokazu Oguni. E-mail: hoguni@ped.twmu.ac.jp).

COMMENT. The authors conclude that a second course of ACTH should be considered to treat a relapse of fIS before resorting to surgical therapy. An extremely low-dose ACTH step-up protocol is used to treat West syndrome (WS) in this institution (Oguni $\mathrm{H}$, et al. Brain Dev 2006 Jan;28(1):8-13). In an earlier report of 31 infants with WS (cryptogenic WS in 9, symptomatic WS in 22) using ACTH-Z in a dose of $0.005 \mathrm{mg}(0.2$ $\mathrm{IU} / \mathrm{kg} /$ day) once daily for at least 2 weeks, up to a maximum of 3 weeks, tapered to zero over the subsequent 1 or 2 weeks, successful control of both spasms and hypsarrhythmia was obtained in 17 patients $(55 \%)$. In the absence of a response, the dosage was increased to $0.025 \mathrm{mg}$ (1.0 IU/kg/day) for 2 weeks (second treatment course in 8 patients), providing complete suppression of WS in an additional 2 patients. At 1 year or more follow-up, 13 patients (48\%) remained seizure-free. Side effects were mild and occurred in 13 patients. This ACTH extremely low-dose step-up method achieved $61 \%$ short-term and $48 \%$ long-term remission, without significant side effects. The efficacy of low-dose versus high-dose ACTH regimens continues to be debated (Ito M, et al. Pediatr Neurol 1990 Jul-Aug;6(4):240-4; Snead OC, et al. Neurology 1989 Aug;39(8):1027-31; Snead OC. Pediatr Neurol 1990 May-Jun;6(3):147-50).

\title{
EVIDENCE-BASED GUIDELINE FOR TREATMENT OF NEUROCYSTICERCOSIS
}

The Guideline Development Subcommittee of the AAN conducted a literature search and review of 10 Class I or Class II trials of treatment for parenchymal neurocysticercosis. Albendazole therapy, with or without corticosteroids, is probably effective in decreasing both long-term seizure frequency and the number of cysts demonstrable radiologically in adults and children with neurocysticercosis, and is welltolerated. Insufficient information is available to assess efficacy of praziquantel. Albendazole plus either dexamethasone or prednisolone should be considered, both to decrease the number of active lesions on brain imaging studies (Level B) and to reduce long-term seizure frequency (Level B). The evidence is insufficient to support or refute the use of steroid treatment alone in patients with intraparenchymal neurocysticercosis (Level U). (Baird RA, Wiebe S, Zunt JR, Halperin JJ, Gronseth G, Roos KL. Evidencebased guideline: Treatment of parenchymal neurocysticercosis. Neurology 2013 Apr 9;80(15):1424-1429). (Respond: AAN. E-mail: guidelines@aan.com). 
COMMENT. Cysticercal cysts evolve through 4 stages: vesicular with living larva, colloidal stage with degenerate larva, granulonodular stage with thickened cyst membrane, and calcification stage. Only cysts in the vesicular and colloidal stages contain the larvae and are amenable to anticysticercal treatment. Cysticercosis, infection with the larval form of Taenia solium, is the most common preventable cause of epilepsy in the developing world (Coyle CM, et al. PLoS Negl Trop Dis 2012;6(5):e1500).

\section{ENCEPHALITIS}

\section{ANTI-N-METHYL-D-ASPARTATE RECEPTOR ENCEPHALITIS}

Investigators at Universities of Barcelona, Pennsylvania, Oviedo, and Valencia, and the Spanish NMDAR Encephalitis Work Group report the clinical features of 20 pediatric patients with anti-N-methyl-D-aspartate receptor (NMDAR) encephalitis seen in a single center in Spain in the last 4 years. Median patient age was 13 years (range, 8 months-18 years); 70\% were female. Initial symptoms were neurologic (dyskinesias or seizures) in $12(60 \%)$ and psychiatric in $40 \%$. By one month after disease onset, all had involuntary movements and changes in behavior and speech. All patients received steroids, IV immunoglobulin or plasma exchange, and 7 rituximab or cyclophosphamide. At a median follow-up of 17.5 months, $85 \%$ had substantially recovered, $10 \%$ had moderate or severe deficits, and 1 had died. Three patients had previous episodes compatible with anti-NMDAR encephalitis, and 2 had additional relapses. Ovarian teratoma was identified in 2 patients $(10 \%), 1$ at disease onset and the other one-year later. A novel characteristic EEG pattern ("extreme delta brush") occurred in one 18year-old patient. A 2-year-old patient developed anti-NMDAR as post herpes simplex encephalitis choreoathetosis; her recovery was complicated by a bilateral facial weakness and anarthria (Foix-Chavany-Marie syndrome). (Armangue T, Titulaer MJ, Malaga I, et al. Pediatric anti-N-methyl-D-aspartate receptor encephalitis - Clinical analysis and novel findings in a series of 20 patients. J Pediatr 2013 Apr;162(4):850-856.e2). (Reprint requests: Josep Dalmau MD, PhD, E-mail: Josep.dalmau@uphs.upenn.edu).

COMMENT. Since the initial description of NMDAR encephalitis (Dalmau J, et al. Ann Neurol 2007 Jan;61(1):25-36), and in children (Florance NR, et al. Ann Neurol 2009 Jul;66(1):11-8), this encephalitis has been reported frequently as single case histories, small series, and in one large series of 500 patients (Titulaer MJ, et al. Neurology 2012 Apr; 78(Meeting Abstracts 1): PL01.001). The present series in children adds to our experience with this intriguing disorder and increases our awareness of the presenting symptoms and diagnosis. The rare link between NMDAR encephalitis and post herpes simplex encephalitis choreoathetosis, and the etiologic significance of ovarian teratoma require further study. The "delta brush" EEG pattern in one patient, previously described in $30 \%$ of an adult cohort, may be unique to NMDAR encephalitis and correlates with disease severity (Schmitt SE, et al. Neurology 2012 Sep 11;79(11):1094-1100). 